Dhaka University J. Biol. Sci. 29(1): 97-105, 2020 (January)

\title{
ASSOCIATION AMONG SELF-ESTEEM, AGGRESSION AND PSYCHOLOGICAL ADJUSTMENT OF ORPHANS AND FAMILY-REARED CHILDREN
}

\author{
Nahida Sultana And Mahfuza Khanam* \\ Department of Psychology, University of Dhaka, Dhaka 1000, Bangladesh
}

Key words: Self-esteem, Aggression, Psychological adjustment, Orphans children

\begin{abstract}
The present study explored the relationship among self-esteem, aggression, and psychological adjustment between orphan children and family-reared children. The sample comprised of 160 adolescents. Out of the total sample, 80 were living in the orphanages; and 80 participants were living with their both parents. They were selected by employing purposive-incidental sampling technique. Participants responded to the index of the Personal Information Form (PIF), Bangla version of Rosenberg Self-Esteem scale, Bangla version of BussPerry Aggression Questionnaire, and Bangla version of Adolescent Personality Assessment Questionnaire. Results showed that key variables were significantly correlated with one another. Results indicated that the children in orphanages have lower self-esteem, are more aggressive, and have higher psychological adjustment problem than children living with their both parents. Results also showed that girls have lower self-esteem and they are less aggressive than boys. Self-esteem has been found to be an important predictor of psychological adjustment of the respondents. Therefore, the findings of present research will encourage our perceptive of self-esteem and will advance the understanding about the negative impact of aggression on children's mental health.
\end{abstract}

\section{Introduction}

The stage of adolescence period is an important part of student's life as he or she moves from total dependence on the family, educator, and core curriculum into the whole independence. This provisional period can bring up concerns of independence and self-identity. It is known that adolescent's life has its own demands and challenges. Failure in meeting those demands and challenges may cause aggression, low self-esteem, and psychological problems for them. Therefore, it is important to guide adolescents to adjust in order to avoid those problems and achieve their goal.

Self-esteem refers to one's self-confidence or the manners in which a person judges and evaluates himself/herself. It also refers to an individual's sense of his or her value or worth, or the extent to which a person values, approves of, appreciates, prizes, or likes him or

\footnotetext{
${ }^{1}$ Author for correspondence: <mahfuzakhanam007@yahoo.com>.
} 
herself ${ }^{(1)}$. This attribute is more important in adolescence children, because adolescence is considered as one of the dominant and main processes of social and psychological growth of personality. High self-esteem refers to positive view of ourselves which tends to lead to confidence in our own abilities; self-acceptance; optimism and not worrying about what others think (2). People with low self-esteem, however, would tend to be at risk anxiety, aggression, depression, and feelings of unworthiness ${ }^{(3)}$.

Self-esteem plays an important role in aggressive behavior, as it is negatively correlated with aggression. That means high level of self-esteem among adolescents is linked to a low level of aggression and low level of self-esteem among adolescents is linked to a high level of aggression ${ }^{(4 ; 5 ;)}$. Psychologist defined aggression as "an act that is intended to cause harm to another person" (6). Some authors suggest that low self-esteem was associated with delinquency and aggression, when controlling for narcissism ${ }^{(7)}$. There is significant gender difference in aggression. Boys are more aggressive than girls, simultaneously physical, verbal aggression, anger and hostility is found more among boys than girl students ${ }^{(8 ; 9)}$. A group of psychologist found a robust relation between low self-esteem and externalizing problems such as aggression, antisocial behavior and delinquency ${ }^{(5)}$. A study in Bangladesh also revealed that boys expressed more aggression than girls ${ }^{(10)}$.

Psychological adjustment is an adjustment with the surroundings which offers the ability to satisfy most social and psychological needs. Psychological adjustment concerns mental health aspects such as depressive symptoms, mood disturbances, general wellbeing and satisfaction with life. An orphan is someone whose parents have died, unknown, or have permanently abandoned them. It has been found that family reared adopted children show lower self-esteem than their non-adopted peer groups ${ }^{(11)}$. Family reared adopted children are hypothesized to be at risk of low self-esteem. Low global self-worth is associated with high levels of negative emotionality which in turn is related to aggression ${ }^{(12)}$. Humanistic psychologists ${ }^{(13)}$ have argued that a lack of unconditional positive self-regard is linked to psychological problems, including aggression. Research findings suggested that international adolescent adoptees have lower self-esteem and are at higher risk for developing severe mental health problems and social maladjustment than children of the same age living with their biological families in the general population ${ }^{(14)}$. A study in our country showed that institutionalized children differed significantly in intelligence and self-concept from children in normal homes ${ }^{(15)}$.

The present work was done to see the association among self-esteem, aggression, and psychological adjustment between the orphans and the family-reared children's in Bangladeshi context because the number of aggressive behaviors are increasing day by day and affecting the school aged children's psychological wellbeing and social functioning. This present study shall thereby help to identify the difference between boys and girls on self-esteem, aggression, and psychological adjustment of the orphans and 
the children living with their parents. It is also expected that findings of this study may be helpful for school psychologist to develop new strategic. The findings would be useful particularly in a collectivist society like Bangladesh to aware parents, teachers, community and others about how aggression and emotional mal-development impact students' self-esteem in their lives.

In the light of above discussion, the objectives of the present study are: (i) To investigate whether there is any correlation exists among self-esteem, aggression and psychological adjustment of the orphans and the family-reared children. (ii) To determine whether there is any mean difference between the orphans and the familyreared children in self-esteem, aggression and psychological adjustment. (iii) To investigate whether there is any gender difference in self-esteem, aggression and psychological wellbeing of the orphans and the children living with their both parents. (iv) To investigate whether self-esteem and aggression can predict the variance of psychological adjustment of the orphans and the children living with parents.

\section{Materials and Methods}

Non-probability sampling (purposive sampling and convenience sampling) techniques were followed during the selection of the sample. The sample comprised of 160 adolescents. Out of the total sample, 80 participants were living in orphanages (40 boys and 40 girls); and 80 participants were living with their both parents ( 40 boys and 40 girls). The inclusion-exclusion criteria were: (1) children willing to participate in the current research (2) the age range between 13 - 16 years and (3) the orphans must be living in orphanages for the past 3 - 5 years whereas those children who are living with their parents should not have any history of parental loss by death or divorce.

The following instruments were used to collect data: (i) The Personal Information Form (PIF), (ii) Bangla version of Rosenberg self-esteem scale ${ }^{(16,17)}$. (iii) Bangla version of Buss-Perry Aggression Questionnaire (BPAQ) ${ }^{(18,19)}$. (iv) Adolescent Personality Assessment Questionnaire (Adolescence PAQ) Short Form(20-22).

The personal information form (PIF): The PIF include demographic, personal, and social information about respondent's gender, age, educational qualification, number of siblings, birth order, etc.

Rosenberg's self-esteem scale: An adapted Bangla version of Rosenberg self-esteem scale was used ${ }^{(17)}$ in the present study. The scale was originally developed ${ }^{(17)}$ to measure adolescent's feeling of self-worth or self-acceptance. Ii is a ten item Likert type scale with four point response format (strongly agree, agree, disagree, strongly disagree). The score ranges from 10 - 40 with higher score representing higher self-esteem. Five items estimate positive feelings and five items estimate negative feelings about self. Items 3, 5, 8, 9, 10 are reversed scored. The test-retest correlations are typically in the range of 0.82 to 0.88 , and Cronbach alpha for various samples were in the range of 0.77 to 0.88 . 
Bangla version of buss-perry aggression questionnaire (BPAQ): An adapted Bangla version of Buss-Perry Aggression Questionnaire(18) scale was used. The scale was originally developed by ${ }^{(20)}$ to measure adolescent's aggression toward others. It is a 27 item Likert type scale with a 5-point response format (totally disagree, partially disagree, neutral, partially agree, totally agree) ranging from (5) "totally agree" to (1) "totally disagree." The score ranges from 27 - 135 with higher score representing higher aggression. Test-retest reliability coefficient was (r $30=0.79, \mathrm{p}<0.05)$ significant and provided highly satisfactory level of temporal stability of the Bangla version of the BussPerry Aggression Questionnaire and Cronbach's Alpha was found 0.74 for 70 cases. The split-half reliability coefficient between the odd-even numbers of items was found 0.74 after using the Spearman-Brown correlation formula. So, the Bangla version of the BussPerry Aggression Questionnaire (BAPQ) could be considered as reliable scale to measure aggression.

The adolescents version (short form) of the personality assessment questionnaire (Adolescent's PAQ): The Adolescents version (short form) of the Personality Assessment Questionnaire was originally developed by ${ }^{(20)}$ to asses psychological adjustmentmaladjustment. The Bangla version of the Adolescent's $\mathrm{PAQ}^{(21)}$ was used to measure adolescent overall psychological adjustment of the respondents. Adolescent's respond to PAQ items on a 4-point Likert-type scale ranging from (4) "almost always true of me" to (1) "almost never true of me." A profile of an adolescent's overall self-reported psychological adjustment is achieved by summing the seven scale-scores after reverse scoring appropriate items. They include: (1) hostility/aggression, (2) dependence, (3) impaired self-esteem, (4) impaired self-adequacy, (5) emotional unresponsiveness, (6) emotional instability and (7) negative worldview. The PAQ has been used in several hundred studies internationally, and it has been shown to have high reliability and validity in cross-cultural research ${ }^{(20,22)}$. The possible scale score ranges from a low of 42 to a high of 210. Psychological maladjustment is indicated if the total PAQ score is at or above the scale midpoint 105 . On the other hand, psychological adjustment is indicated if the total PAQ score is below the scale midpoint 105. The questionnaire found to be reliable and valid for use in cross-cultural research with a coefficient of alpha $.86^{(20)}$.

A cross-sectional survey research design was followed for conducting the present study. This design indicates that all data were collected at a single point in time.

After taking permission from the school authority and getting informed consent from the participant, the questionnaires were given to each participant individually in the classroom situation. Although the questionnaires contained written instruction, the students were given extensive verbal instruction to further clarify the task and the meaning of some of the items. They were also required not to omit any item in the questionnaire. They were assured that the data would be kept confidential and would be used only for research purpose. After accomplishment of their task, the answered 
questionnaires were collected from them and they were given thanks. Same procedure was followed during data collection in orphanage. It took one month to collect all the data.

\section{Results and Discussion}

Pearson product moment correlation was completed among the variables of selfesteem, aggression and psychological adjustment between adolescents of orphanage and living homes. Differences between living conditions and gender among the variables of self-esteem, aggression, and psychological adjustment were calculated, using independent sample t-test. After that multiple regression analysis was conducted where psychological adjustment was criterion variable and self-esteem and aggression were predictor variables.

Table 1. Simple correlations among self-esteem, aggression and psychological adjustment.

\begin{tabular}{llll}
\hline Variables & 1 & 2 & 3 \\
\hline 1. Self-esteem & 1 & & \\
2. Aggression & $-0.41^{* *}$ & 1 & \\
3. Psychological adjustment & $0.50^{* *}$ & $-0.019^{*}$ & 1 \\
\hline
\end{tabular}

${ }^{* *}$ Correlation is significant at the 0.01 level (2-tailed). ${ }^{*}$ Correlation is significant at the 0.05 level (2-tailed).

In Table 1, results showed that self-esteem was negatively correlated with aggression (BAPQ) $[r=-0.41, p<0.01]$. That means high level of self-esteem among adolescents is linked to a low level of aggression and low level of self-esteem among adolescents is linked to a high level of aggression. The finding is consistent with some recent studies $^{(4,5,6)}$. The results also showed that self-esteem was positively correlated with psychological adjustment $[\mathrm{r}=0.50, \mathrm{p}<0.01]$ which indicated that students with high selfesteem have better psychological adjustment and students with low self-esteem are vulnerable to psychological maladjustment. From the results, we can also see that aggression was negatively correlated with psychological adjustment $[\mathrm{r}=-0.19, \mathrm{p}<0.05]$. These findings are partially consistent with some recent studies ${ }^{(1,14)}$.

The results of the Table 2, revealed that orphans and family-reared children significantly differ from one another in terms of all the major variables investigated in our study (i.e., self-esteem, aggression, and psychological adjustment). Descriptive statistics showed that the difference in self-esteem between the orphans $(\mathrm{M}=24.22, \mathrm{SD}=$ 3.20), and the family-reared children's $(M=27.01, S D=2.78)$ was significant $(t=-5.87$, $\mathrm{p}<0.01$ ). That means family-reared children's had higher self-esteem than the orphans. This result is supported by the research findings of many investigators ${ }^{(14)}$. Significant 
difference $(\mathrm{t}=14.15, \mathrm{p}<0.01)$ was found in BAPQ between the orphans $(\mathrm{M}=98.25$, $\mathrm{SD}=$ $15.11)$, and the family-reared children's $(M=67.55, S D=12.16)$. Which indicates orphans were vulnerable to be imposed more aggression, hostile, psychological problems than family-reared children's. This result is partially supported by the findings of previous studies (13). Descriptive statistics also showed that the difference in PAQ between the orphans $(\mathrm{M}=109.04, \mathrm{SD}=11.87)$, and the family-reared children's $(\mathrm{M}=118.65, \mathrm{SD}=13.94)$ was significant $(t=-4.69, \mathrm{p}<0.01)$, i.e. orphans had lower psychological adjustment than family-reared children's $(t=-4.69, \mathrm{p}<0.01)$. This finding is also partially consistent with some recent studies ${ }^{(13)}$.

Table 2. Descriptive statistics and living differences in major variables.

\begin{tabular}{|c|c|c|c|c|c|c|}
\hline \multirow[t]{2}{*}{ Variables } & \multicolumn{2}{|c|}{ Orphans $(\mathrm{n}=80)$} & \multicolumn{2}{|c|}{$\begin{array}{c}\text { Family-reared } \\
\text { children's }(n=80)\end{array}$} & \multirow[t]{2}{*}{$t$ test } & \multirow[t]{2}{*}{$\begin{array}{c}\text { Sig. } \\
\text { (2 tailed) }\end{array}$} \\
\hline & Mean & $\mathrm{Sd}$ & Mean & $\mathrm{Sd}$ & & \\
\hline Self-esteem & 24.22 & 3.20 & 27.01 & 2.78 & -5.87 & 0.000 \\
\hline BAPQ & 98.25 & 15.11 & 67.55 & 12.16 & 14.15 & 0.000 \\
\hline PAQ & 109.04 & 11.87 & 118.65 & 13.94 & -4.69 & 0.000 \\
\hline
\end{tabular}

Table 3. Descriptive statistics and gender differences in major variables.

\begin{tabular}{|c|c|c|c|c|c|c|}
\hline \multirow{2}{*}{ Variables } & \multicolumn{2}{|c|}{ Boys $(n=80)$} & \multicolumn{2}{|c|}{ Girls $(n=80)$} & \multirow{2}{*}{$\mathrm{t}$ test } & \multirow{2}{*}{$\begin{array}{c}\text { Sig. } \\
\text { (2 tailed) }\end{array}$} \\
\hline & Mean & $\mathrm{Sd}$ & Mean & $\mathrm{Sd}$ & & \\
\hline Self-esteem & 27.05 & 2.76 & 24.18 & 3.18 & 6.07 & 0.000 \\
\hline BAPQ & 88.51 & 20.23 & 77.28 & 19.50 & 4.36 & 0.000 \\
\hline PAQ & 118.35 & 14.57 & 109.33 & 11.33 & 3.57 & 0.000 \\
\hline
\end{tabular}

In Table 3, in terms of gender difference, it has been found that boys scored significantly higher on self-esteem $(\mathrm{t}=6.07, \mathrm{p}<0.01)$ and had better psychological adjustment $(t=3.57, p<0.01)$ in comparison to girls. Boys are genetically stronger than girls, enjoy liberty in many spheres of life, and opportunities are more open for their growth and development. In our society, males and females often differ in their patterns of development and types of socialization which, in turn, shapes their self-esteem, and psychological adjustment. This may be the reason that male's self-esteem is higher and they have better psychological adjustment in comparison to female adolescents. Results also revealed that boys scored significantly higher on aggression than girls $\quad(t=4.36, p<$ 0.01 ). The reason may also be lying in the process of socialization or social upbringing of boys and girls. Girls are not supported to be aggressive while it may be considered as a 
positive characteristic for boys. This finding is in conformity with the previous reports $(5,8,10)$.

Table 4. Regression of psychological adjustment on self-esteem and aggression of orphans $(n=80)$ and the family-reared children's $(n=80)$.

\begin{tabular}{lcllllll}
\hline & \multicolumn{3}{c}{ Boys } & & \multicolumn{3}{c}{ Girls } \\
\cline { 2 - 4 } \cline { 6 - 8 } Variables & $\mathrm{B}$ & $\mathrm{SE}$ & $\beta$ & & $\mathrm{B}$ & $\mathrm{SE}$ & $\beta$ \\
\hline Self-esteem & 0.86 & 0.64 & 0.16 & & 2.39 & 0.43 & $0.67^{* * *}$ \\
Aggression & -0.29 & 0.08 & $-0.41^{* * *}$ & & 0.213 & 0.07 & $0.36^{*}$ \\
$\mathrm{R}^{2}$ & $0.25^{* * *}$ & & & & $0.26^{* * *}$ & & \\
\hline
\end{tabular}

$\mathrm{B}=$ unstandardized regression coefficient, $\mathrm{SE}=$ unstandardized standard error, $\beta=$ standardized regression coefficient, values within parentheses indicate value of Adjusted $R^{2} ;{ }^{* * *} \mathrm{p} \varangle 0.05$.

Regression analysis was conducted assuming self-esteem and aggression to be predictor variables of psychological adjustment. Table 4 indicates that both self-esteem and aggression are not significant predictors of psychological adjustment for orphans. But, both self-esteem and aggression are significant predictors of psychological adjustment for family-reared children's. The value of adjusted $R^{2}$ indicates, self-esteem and aggression jointly explain only $2.3 \%$ variance in psychological adjustment for orphans. On the other hand, self-esteem and aggression jointly explain 55\% variance in psychological adjustment for family-reared children.

Table 5. Regression of psychological adjustment on self-esteem, and aggression of boys $(n=80)$ and girls $(n=80)$.

\begin{tabular}{lllllllll}
\hline & \multicolumn{3}{c}{ Orphans } & & \multicolumn{3}{c}{ Family-reared children } \\
\cline { 2 - 4 } \cline { 7 - 8 } Variables & $\mathrm{B}$ & $\mathrm{SE}$ & $\beta$ & & $\mathrm{B}$ & $\mathrm{SE}$ & $\beta$ \\
\hline Self-esteem & 0.36 & 0.44 & 0.099 & & 3.09 & 0.38 & $0.61^{* * *}$ \\
Aggression & -0.13 & 0.09 & -0.16 & & 0.39 & 0.09 & $0.34^{* * *}$ \\
$\mathrm{R}^{2}$ & 0.023 & & & & $0.55^{* * *}$ & & \\
\hline
\end{tabular}

$\mathrm{B}=$ unstandardized regression coefficient, $\mathrm{SE}=$ unstandardized standard error, $\beta=$ standardized regression coefficient, values within parentheses indicate value of Adjusted $R^{2} ;{ }^{* * *} \mathrm{p}<0.001 \&{ }^{*} \mathrm{p}<$ 0.05 .

Table 5 showed that self-esteem is not a significant predictor of psychological adjustment for boys. But, self-esteem is a significant predictor of psychological adjustment for girls. Results also showed that aggression is a significant predictor of psychological adjustment for both boys and girls. The value of adjusted $R^{2}$ indicates, selfesteem and aggression jointly explain $25 \%$ variance in psychological adjustment of boys. 
On the other hand, self-esteem and aggression jointly explain $26 \%$ variance in psychological adjustment of girls.

However, several limitations of this study need to be noted that might have precluded us from obtaining more expected findings. First of all, participants were selected only for employing convenient sampling technique. It was not representative for all the population of Bangladesh. Second, data in our present study was obtained using self-report measurement. There is a possibility that students may be influenced by social demands while responding, thus introducing bias into the results. Finally, the questionnaire administered to the sample was too long. Some participants might have hidden their true feelings which could not verified. However, further study should be conducted to explain the inter-correlations among the factors more rigorously. Despite these limitations, the results of this study provide valuable information for future researchers and practitioners, who are interested in this issue.

\section{References}

1. Blascovich J and J Tomaka 1991. Measures of self-esteem. In: J. P. Robinson, P. R. Shaver, and L.S. Wrightsman (Eds.) Measures of personality and social psychological attitudes, vol. 1. SanDiego, CA. Academic Press.

2. Rogers C. Personality development. Retrieved on July 1, 2009 from http://www.simplypsychology. pwp.blueyonder.co.uk/carlrogers.html, 1959.

3. Rosenberg M, Schooler C and Schoenbach C 1989. Self-esteem and adolescent problems: Modeling reciprocal effects. American Sociological Review 54: 1004-1018.

4. Ostrowsky MK 2009. Are violent people more likely to have low self-esteem or high selfesteem? Aggression and Violent Behaviour 15: 69-75.

5. Donnellan MB, Trzesniewski KH, Robins RW, Moffitt TE and Caspi 2005. Low self-esteem is related to aggression, antisocial behavior, and delinquency. American Psychological Society 4: 328-335.

6. Bernstein DA, Penner LA, Clarke-Stewart A, Roy EJ 2006. Psychology (7th ed) Boston: Houghton Mifflin.

7. Barry CT, Grafeman SJ, Adler KK and Pickard JD 2007. The Relation among narcissism, selfesteem, and delinquency in a sample of at- risk adolescents. Journal of Adolescence 30(6): 933-942.

8. Wani MA, Sankar R, Raghavi R, Chinmaya B. 2017 Aggression among Annamalai University students. Global Journal of Intellectual \& Developmental Disabilities 1(3): 555562.

9. Afroz $\mathrm{N}$ and Huq MM 1999. Effects of residential background, age and gender differentiation on aggressive behavior of children in Rajshahi city. Rajshahi University Studies. Part-B, Journal of Science, 27: 12-19.

10. Begum Roquia 1997. Sex differences in aggressive behavior in children: Parents and teachers' reports. The Bangladesh Journal of Psychology 16: 81-90. 
11. Juffer FH, Marinus V, Ijzendoorna. Adoptees do not lack self-esteem: A meta-analysis of studies on self-esteem of transracial, international, and domestic adoptees Retrieved on July 1, 2009 from http:/wwww.eric.ed. gov/ERICwebportal/custom/portlets/recordDetails/ detail mini.jsp? nfpb..., 2007.

12. Rydell AM, Berlin L and Bohlin G 2003. Emotionality, emotion regulation, and adaptation among 5- to 8-year old children. Emotion 3: 30-47.

13. Rogers CR 1961. On becoming a person. Boston: Houghton Mifflin. Mohanty J, Newhill C. Adjustment of international adoptees: Implications for practice and a future research agenda. Children and youth service review, Retrieved, 2009. From http://www. Sciencedirect.com/science? ob=ArticleURL\&_udi=B6V98-GJM3CH1 \&_user... 2006, 28, 384-395.

14. Islam S and Huque P 1996. Behavior problem among the institutionalized children. Dhaka University Journal of Psychology 20: 26-33.

15. Khanam M 1996-97. Cooperative and competitive behavior of male students reared at home and institution. The Bangladesh Journal of Psychology 16: 9-13.

16. Rosenberg M 1965. Society and adolescent self-image. Princeton, NJ: Princeton University Press.

17. Dash A and Singha B 2016. Bangla version of Buss-Perry Aggression Questionnaire, Department of Psychology, University of Dhaka.

18. Buss AH and Perry M 1992. The aggression questionnaire. Journal of Personality and Social Psychology 63: 452-459.

19. Rohner RP and Khaleque A 2005. Personality assessment questionnaire (PAQ): Test Mannual. In: R.P. Rohner and A. Khaleque (Eds.), Handbook for the study of Parental Acceptance and Rejection ( $4^{\text {th }}$ edition, pp. 187-225). Storrs, CT: Rohner Research Publications.

20. Khaleque A and Rohner RP 2002b. Reliability of measures accessing the pancultural association between perceived parental acceptance-rejection and psychological adjustment: A meta-analysis of cross-cultural and intracultural studies. Journal of CrossCultural Psychology 33: 87-99.

21. Jasmine UH and Uddin MK 2007. Adaptation of the Parental Acceptance-Rejection Questionnaire and Personality Assessment Questionnaire in Bangla Language. Bangladesh Psychological Studies 17: 49-70. 